\title{
Expansive soils
}

\section{Definition}

Expansive Soils are soils that have the ability to shrink and/or swell, and thus change in volume, in relation to changes in their moisture content. They usually contain some form of expansive clay mineral, such as smectite or vermiculite, that are able to absorb water and swell, increasing in volume, when they get wet and shrink when they dry. The more water they absorb the more their volume increases. For the most expansive soils volume changes of $10 \%$ are not uncommon (Chen 1988; Nelson \& Miller, 1992).

\section{Introduction}

Many of the world's largest towns and cities, and therefore their arterial transport routes, services and buildings, are founded on clay-rich soils and rocks. These expansive soils can prove to be a substantial hazard to engineering construction due to their ability to shrink or swell with seasonal changes in moisture content, local site changes such as leakage from water supply pipes or drains, changes to surface drainage and landscaping or following the planting, removal or severe pruning of trees or hedges. Houses and other low-rise buildings, pavements, pylons, pipelines and other shallow services are especially vulnerable to damage because they are less able to suppress differential movements than heavier multi-story structures. Pavements are also highly susceptible to damage because of their relative light-weight nature extended over a relatively large area.

The amount by which the ground can shrink or swell is determined by the water content in the near-surface (active) zone; significant activity usually occurs to about $3 \mathrm{~m}$ depth, unless this zone is extended by the presence of tree roots (Driscoll, 1983; Biddle, 1998; Biddle, 2001). During rainfall these soils can absorb large quantities of water becoming sticky and heavy and causing heave, or lifting, of structures, and during prolonged periods of drought they can become very hard, causing shrinkage of the ground and differential settlement. This hardening and softening is known as 'shrink-swell' behaviour, and presents a significant geotechnical and structural challenge to anyone wishing to build on, or in, them. The main factors controlling this behaviour are the clay content and mineralogy, the in-situ effective stresses and the stiffness of the material. Processes such as original geological environment, climate, topography, land-use and weathering affect these factors, and hence shrink-swell susceptibility. 


\section{Where are they found?}

Expansive soils are found throughout many regions of the world, particularly in arid and semiarid regions, as well as where wet conditions occur after prolonged periods of drought. Their distribution is dependent on geology, climate, hydrology, geomorphology and vegetation. Countries where expansive soils occur and give rise to major construction costs include Ethiopia, Ghana, Kenya, Morocco, South Africa and Zimbabwe in Africa; Burma, China, India, Iran, Israel, Japan and Oman in Asia; Argentina, Canada, Cuba, Mexico, Trinidad, USA and Venezuela in the Americas; Cyprus, Germany, Greece, Norway, Romania, Spain, Sweden, Turkey and UK in Europe; and Australia (Figure 1).

In large areas of these countries the evaporation rate is higher than the annual rainfall so there is usually a moisture deficiency in the soil. When it rains the ground swells and increases the potential for heave. In semi-arid regions a pattern of short periods of rainfall followed by periods of drought can develop, resulting in seasonal cycles of swelling and shrinkage; in humid climates problems with expansive soils trend to be limited to those containing higher plasticity clays; and in arid climates even moderately plastic soils can cause damage to residential property. The literature is full of studies, from all over the world, concerned with problems associated with expansive clays (Fredlund \& Rahardjo, 1993; Stavridakis, 2006; Hyndman \& Hyndman, 2009).

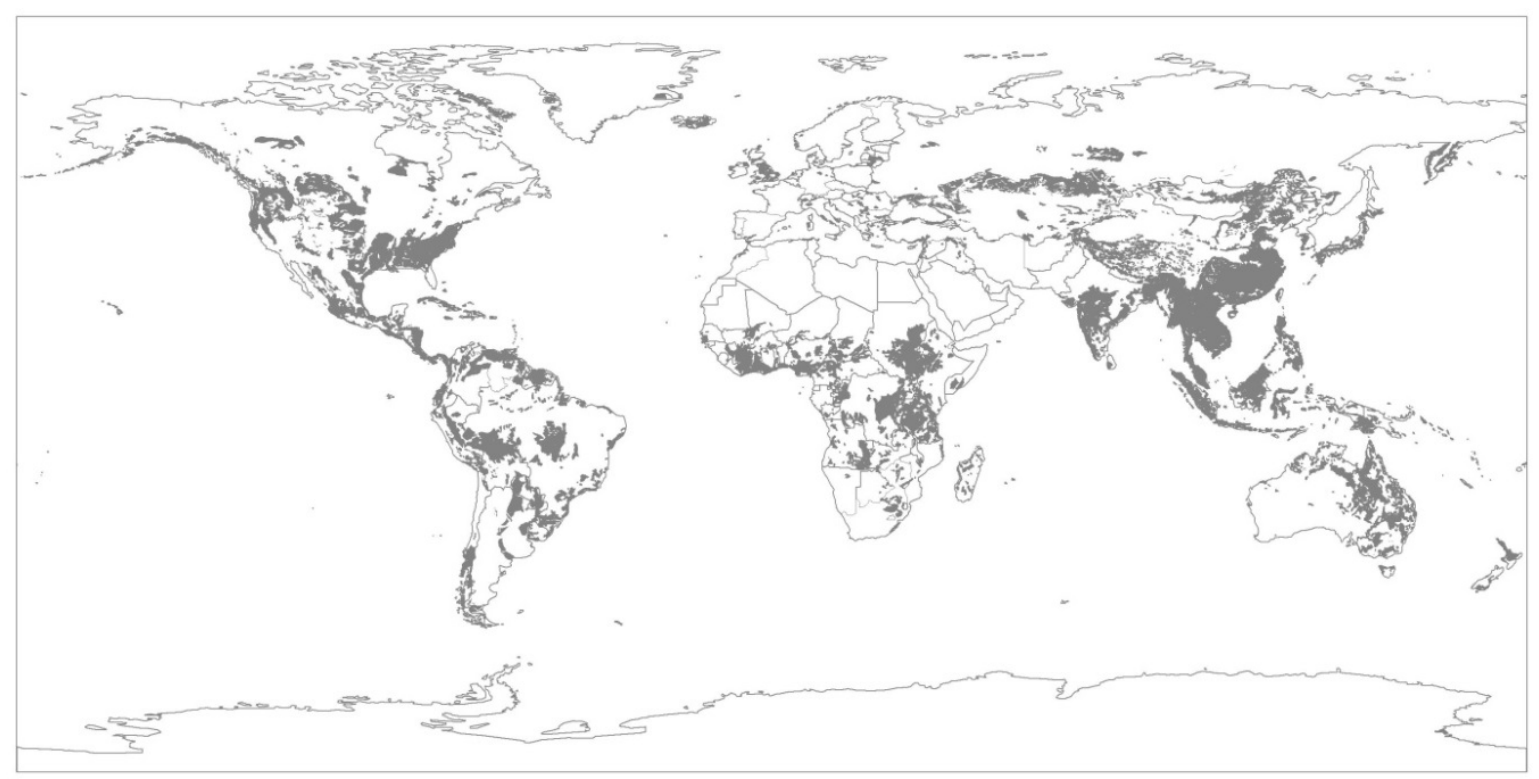

Figure 1 - Global distribution of shrink-swell soil where major construction costs occur (by region) 
In the UK, towns and cities built on clay-rich soils most susceptible to shrink-swell behaviour are found mainly in the south-east of the country, south of a line from Dorset to the North Yorkshire coast (Figure 2). Here many of the 'clay' formations are too young (Jurassic or younger) to have been changed into stronger 'mudstones', leaving them still able to absorb and lose moisture. These deposits are normally firm to very stiff clays or very weak mudstones that weather to firm to stiff clays near the surface. Clay rocks elsewhere in the country are older and have been hardened by processes resulting from deep burial; they are less prone to shrink-swell behaviour because they contain less active clay minerals and are less able to absorb water. Some areas (e.g. around The Wash, northwest of Peterborough, and under the Lancashire Plain) are deeply buried beneath other (superficial) soils that are not susceptible to shrink-swell behaviour. However, other superficial deposits such as alluvium, peat and laminated clays can also be susceptible to soil subsidence and heave (e.g. in the Vale of York, east of Leeds, and in the Cheshire Basin). In the UK, some Mesozoic and Tertiary clay soils and weak mudrocks are also susceptible to shrinkage and swelling as environmental conditions change (Harrison et al., 2012).

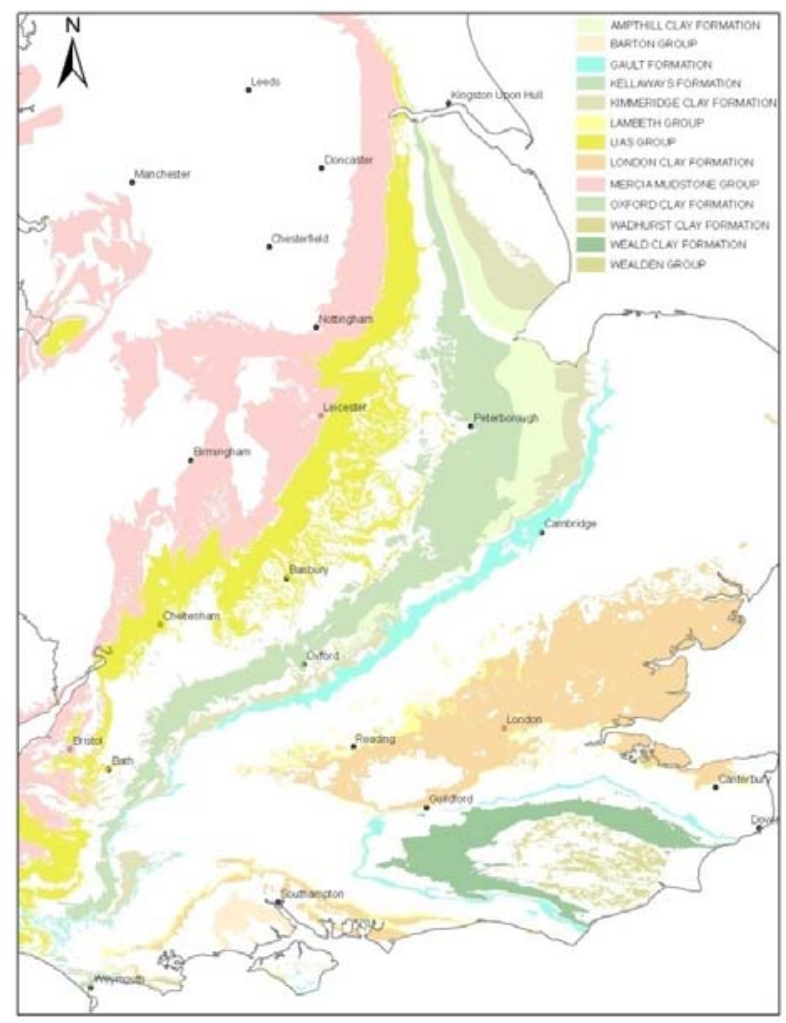


Whilst the distribution of UK clay soils is relatively well known in 2-D, e.g. Loveland (1984), Jeans (2006 a and b) and Wilson et al. (1984), the 3-D distribution is less well known. A meaningful assessment of the shrink-swell potential of any soil requires a considerable amount of high-quality and well-distributed spatial data of a consistent standard (Jones \& Jefferson, 2012) and from this a Volume Change Potential (VCP) map can be constructed. However, looking at soils on a national scale (although giving a good indication of potential problem areas) does not tell the whole story, therefore it is better to look at them on a more regional scale. Jones and Terrington (2011) discuss a methodology for creating a 3D VCP interpolation of the London Clay, visualising plasticity values at a variety of depths, relative to ground level, across the outcrop (Figure 3).

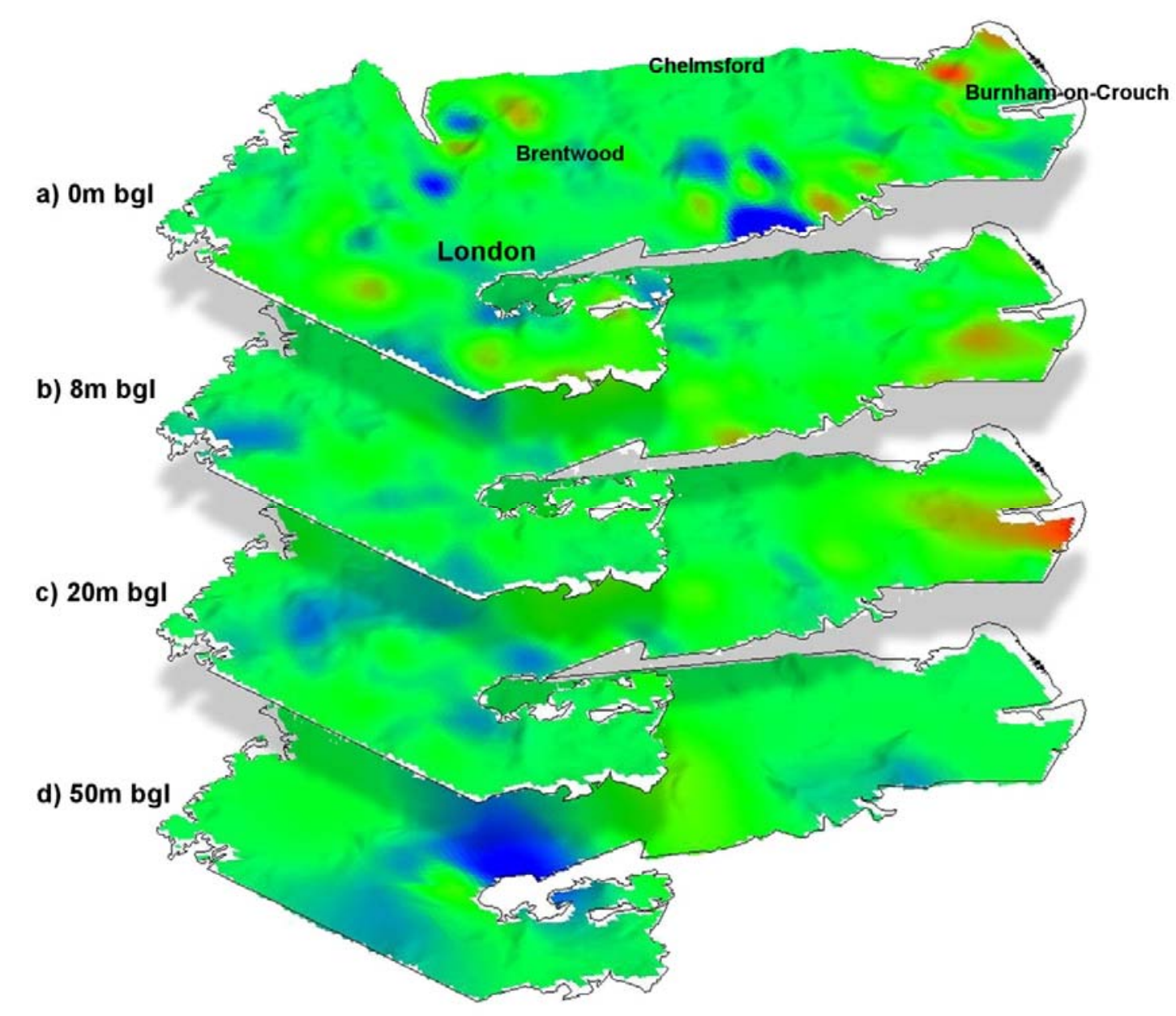

Figure 3 - Interpolation of 'Area 3' showing surfaces at 0m, 8m, 20m and 50m below ground level (Jones \& Terrington, 2011)

[NOTE: blue: medium, green: high, red: v. high] 


\section{What is the Damage?}

Expansive soils were first acknowledged as a major cause of foundation damage following the drought of 1947, since when insurance claims have dramatically increased. In 1991 claims peaked at over $£ 500$ million, and over the past 20 years the Association of British Insurers has estimated that damage caused by expansive soils has cost the insurance industry over $£ 400$ million a year (Driscoll \& Crilly, 2000), making it the most damaging geological hazard in the UK. In fact, one in five homes in England and Wales are at risk from ground that swells when it gets wet and shrinks as it dries out (Jones, 2004), although susceptible ground conditions are perhaps less severe under a temperate UK climate than in some other countries. The American Society of Civil Engineers has estimated that as many as one in four homes in the continental United States has some damage caused by expansive soils, with the annual cost of damage to buildings and infrastructure exceeding $\$ 15$ billion. In a typical year they cause a greater financial loss to property owners than earthquakes, floods, hurricanes and tornadoes combined (Nelson \& Miller, 1992).

Expansive soils can cause heaving of structures when they swell and differential settlement when they shrink. Damage to a structure is possible when as little as 3\% volume expansion takes place (Jones, 2002), especially where these changes are distributed unevenly beneath the foundations. If the water content of a clay soil around the edge of a building changes, the swelling pressure will also change, whilst the water content of the soil beneath the centre of the building remains constant, causing a failure known as end lift (Figure 4). Where the swelling is concentrated beneath the centre of the structure (or where shrinkage takes place under the edges) a failure known as centre lift takes place.

Another major contributing factor to ground shrinkage is tree growth, more specifically tree roots. Roots will grow in the direction of least resistance and where they have the best access to water, air and nutrients (Roberts 1976). The actual pattern of root growth depends upon the type of tree, depth to water table and local ground conditions. Damage to foundations resulting from tree growth occurs in two principal ways:

- Physical disturbance of the ground - caused by root growth and often seen as damage to pavements and walls

- Shrinkage of the ground - caused by water removal and often leading to differential settlement of building foundations 
Vegetation induced changes to water profiles can also have a significant impact on other underground features, including utilities. Tree induced movement has the potential to be a significant contributor to failure of old pipes located in clay soils near deciduous trees (Clayton et al., 2010).

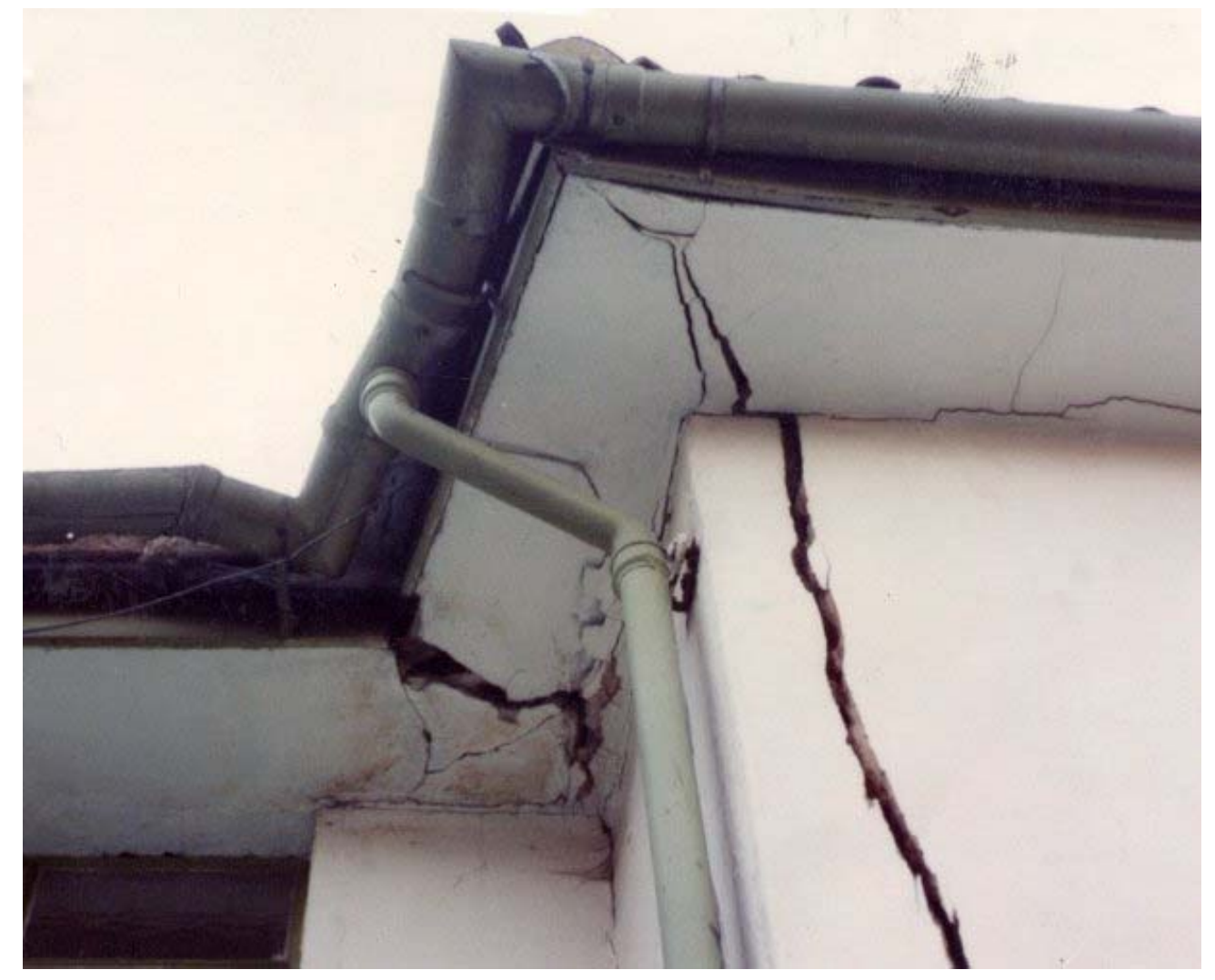

Figure 4 - Structural damage to house caused by 'end lift’ (@ Peter Kelsey \& Partners)

Building, or paving, on previously open areas of land, such as the building of patios and driveways, can cause major disruption to the soil-water system. Sealing the ground in this way cuts off the infiltration of rain water and the trees that are dependent upon this water will have to send their roots deeper, or further afield, in order to find water. The movement of these root systems will cause a major ground disturbance and will lead to the removal of water from a larger area around the tree (Jones \& Jefferson, 2012). Problems occur when structures are situated within the zone of influence of a tree (Figure 5). Pavements are also highly susceptible to damage because of their relative light-weight nature extended over a relatively large area. 


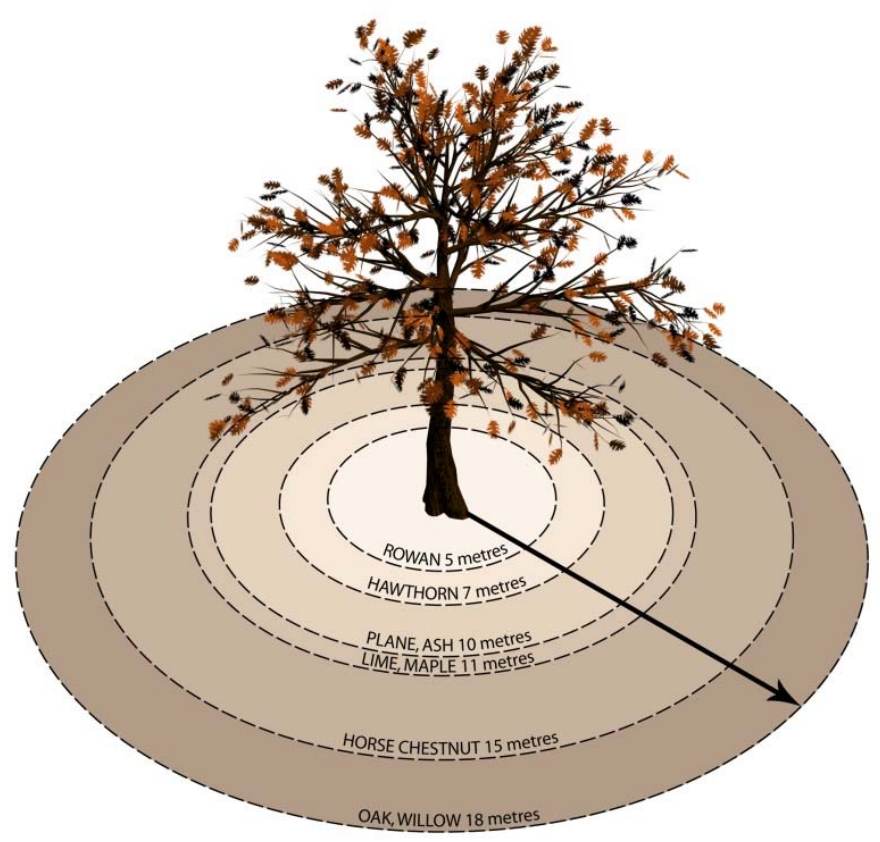

Figure 5 - The zone of influence of some common UK trees (Jones et al., 2006)

\section{Shrink-Swell Behaviour}

The shrink-swell potential of expansive soils is determined by its initial water content; void ratio; internal structure and vertical stresses, as well as the type and amount of clay minerals in the soil (Bell \& Culshaw, 2001). These minerals determine the natural expansiveness of the soil, and include smectite, montmorillonite, nontronite, vermiculite, illite and chlorite. Generally, the larger the amount of these minerals present in the soil, the greater the expansive potential.

Clay particles are very small and their shape is determined by the arrangement of the thin crystal lattice layers that they form. Taylor \& Cripps, (1984), Taylor \& Smith, (1986) and Driscoll, (1983) provide useful reviews of the controls that clay mineralogy has on the drained compressibility/expansibility of geological materials and hence their susceptibility to large deformations from effective stress changes which lead to shrinkage and/or swelling. In expansive clays the molecular structure and arrangement of these crystal layers has an affinity to attract and hold water molecules between them (and on their surfaces) in a strongly bonded 'sandwich', giving them a large shrink-swell potential. For further details of the mineralogy of clay minerals and their influence of engineering properties of soils see Mitchell \& Soga (2005). 
Potentially expansive soils are initially identified by undertaking particle size analyses to determine the percentage of fine particles in a sample. Clay sized particles are considered to be less than $2 \mu \mathrm{m}$ (although this value varies slightly throughout the world) but the difference between clays and silts is more to do with origin and particle shape. Silt particles (generally comprising quartz particles) are products of mechanical erosion whereas clay particles are products of chemical weathering and are characterised by their sheet structure and composition.

Soils with high shrink-swell potential will not usually cause problems as long as their water content remains relatively constant. This is controlled by the soil properties (mineralogy); suction and water conditions; water content variations; and geometry and stiffness of a structure founded on it (Houston et al., 2011). In a partially saturated soil, suction or water content changes increase the likelihood of damage occurring. In a fully saturated soil the shrink-swell behaviour is controlled by the clay mineralogy.

\section{Expansive Soils in Construction}

Potential shrinkage and/or swelling from these causes can usually be anticipated in most engineering circumstances. However, because of the differences between natural and treeinduced shrink-swell, and varying initial conditions, the relative susceptibility to volume change at any place may not necessarily always be the same for a given geological formation or soil type. Houses and other low-rise buildings, pavements, pylons, pipelines and other shallow services are especially vulnerable to damage from shrink-swell clays because they are less able to suppress differential movements than heavier multi-story structures.

Due to the global distribution of shrink-swell soils many different ways to tackle the problem have been developed and these can vary considerably (Radevsky, 2001). These methods depend not only on technical developments but the legal framework and regulations of a country, insurance policies and the attitude of insurers, experience of the engineers and other specialists dealing with the problem and, most importantly, the sensitivity of the owner of the property affected. A summary of these issues is provided by Radevsky (2001) in his review of how different countries deal with shrink-swell soil problems, and a detailed informative study from the United States has more recently been presented by Houston et al. (2011).

Shrink-swell soils require extensive site investigation in order to provide sufficient information. Normal investigations, relating to the structures most affected by shrink-swell soils, are often not adequate. These investigations may involve specialist test programmes even 
for relatively light weight structures (Nelson \& Miller, 1992). Although there are a number of methods available to identify shrink-swell soils, each with their relative merits, there are no universally reliable methods available (Jones \& Jefferson, 2012), and they are rarely employed in the course of routine site investigations in the UK. This means that few data are available for data-basing the directly measured shrink-swell properties of the major clay formations, and reliance has to be placed on estimates based on index parameters, such as liquid limit, plasticity index, and density (Reeve et al., 1980; Holtz \& Kovacs, 1981; Oloo et al., 1987). No consideration has been given to the saturation state of the soil and therefore to the effective stress or pore pressures within it. For further details on the strategies for dealing with the engineering issues and management of expansive soils see Jones \& Jefferson (2012).

\section{Summary}

Expansive soils are found throughout many regions of the world and the subsidence and heave problems associated with them causes billions of pounds of damage annually, making them one of the most costly and widespread geological hazards to domestic properties and other lowrise structures. In arid/semi-arid regions their ability to take up large quantities of water can cause major damage to structures, whereas in more humid regions, such as the UK, problems mainly occur in the more highly plastic soils, especially after prolonged periods of drought. Either way, expansive soils have the potential to demonstrate significant volume change in direct response to changes in water content, induced through water ingress, modification to local water conditions, or via the action of external influence such as trees.

The shrink-swell hazard is controlled by a number of factors, primarily, the geology and mineralogy and the climate. Shrinkage and swelling usually occurs in the near-surface to depths of about $3 \mathrm{~m}$, water content in this upper layer is significantly influenced by climatic and environmental factors and is generally termed the active zone. The shrink-swell potential of expansive soils is determined by its initial water content; void ratio; internal structure and vertical stresses, as well as the type and amount of clay minerals in the soil.

To understand and hence engineer expansive soils in an effect way it is necessary to understand soil properties, suction/water conditions, temporal and spatial water content variations, and the geometry/stiffness of foundations and associated structures. 


\section{Bibliography}

Bell, F.G. and Culshaw, M.G. (2001) Problem Soils: A review from a British perspective. In: Problematic Soils Symposium, Nottingham. (eds Jefferson, I., Murray, E.J., Faragher, E. and Fleming, P.R.), November 2001, 1-35

Biddle, P.G. (1998) Tree roots and foundations. Arboriculture Research and Information Note 142/98/EXT

Biddle, P.G. (2001) Tree Root Damage to Buildings. Expansive Clay Soils and Vegetative Influence on Shallow Foundations. ASCE Geotechnical Special Publications 115, 1-23

Chen, F.H. (1988) Foundations on expansive soils, Amsterdam: Elsevier

Clayton, C.R.I., Xu, M., Whiter, J.T., Ham, A. and Rust, M. (2010) Stresses in cast-iron pipes due to seasonal shrink-swell of clay soils. Proceedings of the Institution of Civil Engineers: Water Management, 163(WM3), 157-162

Driscoll, R. (1983) The influence of vegetation on the swelling and shrinking of clay soils in Britain. Geotechnique, 33, 93-105

Driscoll R. and Crilly, M. (2000) Subsidence damage to domestic buildings. Lessons learned and questions asked. London: BRE Press

Fredlund, D.G. and Rahardjo, H. (1993) Soil mechanics for unsaturated soils. New York: Wiley

Harrison, A.M., Plim, J., Harrison, M., Jones, L.D. and Culshaw, M.G. (2012) The relationship between shrink-swell occurrence and climate in south-east England. Proceedings of the Geologists' Association, 123(4), 556-575

Holtz, R.D. and Kovacs, W.D. (1981) An introduction to geotechnical engineering. Prentice-Hall, New Jersey

Houston, S.L., Dye, H.B., Zapata, C.E., Walsh, K.D. and Houston, W.N. (2011) Study of expansive soils and residential foundations on expansive soils in Arizona. Journal od Performance of Constructed Facilities, 25(1), 31-44

Hyndman, D. \& Hyndman, D. Natural Hazards and Disasters. Brooks/Cole, Cengage Learning, California, 2009.

Jeans, C.V. 2006a. Clay mineralogy of the Cretaceous strata of the British Isles. Clay Minerals, 41, 47150.

Jeans, C.V. 2006b. Clay mineralogy of the Jurassic strata of the British Isles. Clay Minerals, 41, 187307.

Jones, L.D. (2002) Shrinking and swelling soils in the UK: Assessing clays for the planning process. Earthwise 18. Geology and Planning. British Geological Survey, UK

Jones, L.D. (2004) Cracking open the property market. Planet Earth. Autumn 2004, 30-31

Jones, L.D., Venus, J. \& Gibson, A.D. (2006) Trees and Foundation damage. British Geological Survey Commissioned Report CR/06/225.

Jones, L.D. and Terrington R. (2011) Modelling volume change potential in the London Clay. Quarterly Journal of Engineering Geology and Hydrogeology, 44, 1-15

Jones, L.D. and Jefferson, I. (2012) Expansive soils. In: Burland, J., Chapman, T., Skinner, H., Brown, M. (Eds.), ICE manual of geotechnical engineering. Volume 1 Geotechnical engineering principles, problematic soils and site investigation. London: ICE Publishing, 413-441

Loveland, P.J. 1984. The soil clays of Great Britain: I England and Wales.Clay Minerals, 19, 681-707. 
Mitchell, J.K. and Soga, K. (2005) Fundamentals of Soil Behaviour ( ${ }^{\text {rd }}{ }^{\text {Edition}) . ~ N e w ~ Y o r k: ~ W i l e y . ~}$ Nelson, J.D. and Miller, D.J. (1992) Expansive soils: problems and practice in foundation and pavement engineering. New York: Wiley

Oloo, S., Schreiner, H.D. \& Burland, J.B. (1987) Identification and classification of expansive soils. 6th International Conference on Expansive Soils, December 1987, New Delhi, India, Imperial College of Science and Technology, London, 23-29.

Radevsky, R. (2001). Expansive clay problems - how are they dealt with outside the US? Expansive clay soils and vegetative influence on shallow foundations. ASCE Geotechnical Special Publications 115, 172-191

Reeve, M.J., Hall, D.G.M. and Bullock, P. (1980) The effect of soil composition and environmental factors on the shrinkage of some clayey British soils. Journal of Soil Science, 31, 429-442

Roberts, J. (1976) A study of root distribution and growth in a Pinus Sylvestris L. (Scots Pine) plantation in East Anglia. Plant and Soil, 44, 607-621

Stavridakis, E.I. (2006) Assessment of anisotropic behaviour of swelling soils on ground and construction work. In: Al-Rawas, A.A. \& Goosen, M.F.A. (Eds). Expansive soils: Recent advances in characterization and treatment. Taylor and Francis, London.

Taylor R.K. and Cripps J.C. (1984) Mineralogical controls on volume change. In: Ground movements and their effects on structures, Surrey University Press, 268-302

Taylor, R.K. and Smith, T.J. (1986) The Engineering Geology of Clay Minerals: Swelling, Shrinking and Mudrock Breakdown. Clay Minerals, 21, 235-260

Wilson, M.J., Bain, D.C. and Duthie, D.M.L. 1984. The soil clays of Great Britain: II Scotland.Clay Minerals, 19, 709-735 